\title{
A Preliminary Exploration of Professional Development Instrument for Lecturers in Malaysia
}

Ahmad Faizuddin*, Tajulashikin Jumahat, Mohamad Sahari Nordin

Kulliyyah of Education, International Islamic University Malaysia, Jalan Gombak, 53100, Selangor, Malaysia

*Corresponding author: abmad.faizuddin@live.ïum.edu.my

\section{Article history}

Received: 2018-07-29 Received in revised form: 2020-01-31 Accepted: 2020-01-31 Published online: 2020-06-30

\begin{abstract}
Professional development is crucial for organization's success to improve teaching-learning programs at higher learning education institutions. Many countries have developed various programs for lecturer training and development. However, there are barriers preventing them from taking the opportunities, especially finding the right time and the appropriate programs. This study explored the construct of lecturers' professional development in teaching and learning after attending various trainings and workshops. The main objective of this study is to identify the underlying factor of the instrument based on Kirkpatrick's Four Level Evaluation Framework namely reaction, learning, behaviour, and results. Using an 18-item instrument developed for an explorative inquiry, the present study measured and analysed responses from 100 higher education lecturers from randomly selected Public Higher Learning Institution, Private Higher Learning Institution, and Malaysia Technical University Network. Applying Exploratory Factor Analysis (EFA) to identify the underlying dimensions of the instrument, this study suggested that lecturer's professional development in teaching and learning is a one-dimension construct consisting of integrated dimensions of knowledge enhancement, knowledge relevancy, skills improvement, and skills practice.
\end{abstract}

Keywords: Professional development, knowledge enhancement, knowledge relevancy, skills improvement, skills practice, exploratory factor analysis (EFA) 


\subsection{INTRODUCTION}

Professional development is basically recognized as training, in which educators learn and apply their knowledge into practice to support students' learning (Postholm, 2012). Many countries have developed various programs for lecturer training and development. However, there are many barriers preventing them from taking the opportunities, especially finding the right time and the appropriate programs. Hence, lecturers' professional development is considered important for a better education performance. Not only for a better teaching and learning environment, lecturers' professional development will ultimately improve student and staff welfare and well being (Bubb \& Earley, 2013).

At some points, educators are under pressure to be more productive. In higher learning institution, leaders and lecturers are expected to perform demanding programs to support learning activities (Cahill et al., 2015). This is due to the fact that lecturers' competency will somehow determine both positive and negative world of the higher education students (Dias \& Sá, 2014). Being an educator, a lecturer must have professional identity and professional quality (Pereira, Lopes, \& Marta, 2015) so that they will understand the concept of educational utility that effectuate learning (Subramaniam \& Esprívalo Harrell, 2015). Sometimes they think they are teaching but in fact they are not (Trent, 2014). Thus, the on going training and development programs should be evaluated, reviewed and reshaped to fulfill the demand of the era.

In Malaysia, the Ministry of Higher Education, in accordance with the National Higher Education Strategic Plan, has been conducted various workshops to provide leadership development for top and middle management in Malaysian Higher Education Institutions, such as Leadership for University Community Engagement Workshop, Training for Master Trainers Modular Approach and Learner Diversity, International Conference on Teaching and Learning in Higher Education, Higher Education Learning and Teaching in Technical and Vocational Education and Training (TVET). All of these programs aim to transform The Malaysian Higher education system, especially in the area of human capital development (LeAD Bulletin, 2008).

\subsection{LITERATURE REVIEW}

\subsection{Conceptualing Professional Development Programs}

It is important to note that the conceptualization of lecturers' professional development program calls for specific contextual referent, without which its definitions lacks substantive components. In the present study, the contextual referent for training relates to the course of actions and tasks in the light of its goals as prescribed by the Ministry of Higher Education Malaysia. Thus, this study defines lecturers' professional development program as a four-dimension construct comprising knowledge enhancement, knowledge relevancy, skills improvement, and skills practice.

Together, these four dimensions are anticipated to explain the variability in lecturers' professional development in learning and teaching at higher learning education institutions. In the context of this study, knowledge enhancement means the ability to apply and use the skills to improve teaching and learning. As for knowledge relevancy, it means professional knowledge needed in today's advance environment. Whereas, skills improvement means the effectiveness of lecturers' development program to improve students' achievement, while skills practice means participating in various professional development programs in teaching and learning.

Literatures showed that previous study mostly focused on appropriate content training (Holec, 2011), relevant professional knowledge (Bubb \& Earley, 2013), learning attitude (Dekker-Groen, Van Der Schaaf \& Stokking, 2013), and misaligned practice (Schlager \& Fusco, 2003; Postholm, 2012). For that reason, the current study tries to align the underlying factor of 
lecturers' professional development with the four level of Kirkpatrick's Evaluation. In this regards, each dimension reflects Kirkpatrick's Four Levels Evaluation, i.e. Level 1: Reaction, Level 2: Learning, Level 3: Behavior, and Level 4: Results. The following discussion will elaborate more on these frameworks.

\section{a) Reaction and Knowledge Enhancement}

One of reliable dimensions of lecturers' professional development is knowledge enhancement. This would lead to positive improvement of lecturers' knowledge that will determine their reaction on similarly future programs. Kirkpatrick and Kirkpatrick (2006, p. 21) referred reaction as "a measure of customer satisfaction". It measures how the participants react to the training programs. More importantly, the reaction should be positive to determine future training and ensure motivated learning.

What kind of training is actually needed to produce knowledge enhancement? As stated by Holec (2011), the main objective of providing certain training is to develop the ability of the participants to use relevant knowledge and skills in order to build teaching programs and apply it in the classroom. The emphasis of the training should be focused more on information on the 'whys' as a generative type of the training program. For that reason, appropriate evaluation should be made accordingly.

In order to measure positive reaction, to have the right items are required to better appraise this dimension. "Evaluate reactions on every program even though you think you know what their reactions will be" (Kirkpatrick \& Kirkpatrick, 2007, p. 46). This somewhat indicates the significant of evaluating the reaction influenced by knowledge enhancement.

\section{b) Learning and Knowledge Relevancy}

The second dimension of lecturers' professional development is knowledge relevancy. Most participants will join training programs to update and upgrade their knowledge. They want to learn relevant knowledge, which is reliable in today's teaching and learning activities. Thus, according to Kirkpatrick and Kirkpatrick (2007), "In any training program, there are three possible objectives: 1. For the participants to acquire knowledge related to their jobs, 2. For participants to learn new skills and/or increase their present skills, and 3. For participants to change their attitudes" (p. 47). What is learning then? Learning is defined as to accomplish three things, i.e. "attitudes are changed, knowledge is increased, and skill is improved" as a result of attending the program (Kirkpatrick \& Kirkpatrick, 2006, p. 22).

Schleider (2012) argued that today's educators need to be high-level knowledge workers. Thus, there is a kind of teaching needed to constantly advance educators' professional knowledge (Bubb \& Earley, 2013). In line with the above-mentioned need, Eraut (1994) specifically mentioned that professional education and continuing professional development programs are needed in order to become learning professionals. This assertion signifies the dimension of knowledge relevancy.

\section{c) Behaviour and Skills Improvement}

The third dimension of lecturers' professional development program is skills improvement. One of the ways to see the competency and development of the educators is through students' achievement. Effective educators' competence is in line with the development of students' learning goals (Dekker-Groen, Van Der Schaaf \& Stokking, 2013). The skills improvement is also closely related to changing behavior of a lecturer to make necessary change on students' achievement. What is the meaning of behaviour and how to effectively evaluate it?

According to Kirkpatrick and Kirkpatrick (2006), "Behavior can be defined as the extent to which change in behaviour has occurred because the participant attended the training program. In order for change to occur, four conditions are necessary: 1 . The person must have a desire to 
change, 2. The person must know what to do and how to do it, 3. The person must work in the right climate, and 4. The person must be rewarded for changing" (p. 23). While, evaluating behavior can be done through surveys, questionnaires, interviews, observed behaviors, observation of work, and focus groups. The approach used depends on resources and desire to do it (Kirkpatrick \& Kirkpatrick, 2007). The behavioural change is expected to delineate the dimension of skills improvement.

\section{d) Results and Skills Practice}

The last dimension of lecturers' professional development is skills practice. This is the stage where a participant will know the result of the training he or she has participated by practicing the skills they have acquired. What is the result and how to evaluate it? "Results can be defined as the final results that occurred because the participants attended the program. The final results can include increased production, improved quality, decreased costs, reduced frequency and/or severity of accidents, increased sales, reduced turnover, and higher profits" (Kirkpatrick \& Kirkpatrick, 2006, p. 25).

To evaluate the results, an important point to establish is to start with the end in mind. It is necessary to know the expectations for the program. "In planning training programs, trainers need to look at the desired end results and say to themselves and others, "What behavior on the part of supervisors and managers will achieve these results?" Then they determine, "What knowledge, skills, and attitudes do supervisors need in order to behave in that way?" Finally, they determine the curriculum that will meet the training needs, and proceed to do the things accordingly" (Kirkpatrick \& Kirkpatrick, 2007, p. 109).

While, one of the issues is not all knowledge learnt in training programs is relevant to practice. As the environment and learning practice of each school is different to one another, not all the forms of courses and workshops in the training programs can facilitate educators in learning processes and may not be relevant to school practices (Postholm, 2012). Learning may occur in various ways, including participation in courses, observation of and reflection on others' teaching, planned and unplanned reflection meeting between lecturers, or in trainings or workshops.

Objectively, the purpose of this study is to survey lecturers' effectiveness in teaching and learning in the classroom after attending various trainings and workshops, and in doing so, to clarify the meaning of the construct itself. Thus, the study exploring the underlying dimensions of lecturer's professional development in learning and teaching. More precisely, the study concerned with the development and preliminary validation of a scale to measure lecturer's professional development in learning and teaching at higher learning education institutions.

\subsection{RESEARCH METHOD}

The study employed the survey method to gather information about professional development training and workshop programs related to the objectives of the study. A sample of educators consisting of tutor, lecturer, senior lecturer, associate professor, and professor was selected for this study.

\subsection{Participants}

Participants were 100 educators consisting of tutor, lecturer, senior lecturer, associate professor, and professor from three higher education institutions selected randomly from a list of Public Higher Learning Institution, Private Higher Learning Institution, and Malaysia Technical University Network that participated in an earlier nation-wide survey. They were experienced educators ( $M=14.14$ years); $56 \%$ were males and $44 \%$ were females; $79 \%$ had attended at least one training or workshop. Distribution of the sample indicated that these educators, diverse in 
content specializations, taught students a wide range of school subjects at higher learning level. A preliminary analysis found that there were no serious departures of sample characteristics from the population of higher education educators in Malaysia, hence the sample can be as representative of much of the population.

To satisfy the requirement for an adequate sample size, the study subscribed to the principle derived from Bartlett, Kortlik and Higgins (2001) and Gorsuch (1983), in which noted that factor analysis should be done with no less than 100 observations. Guadagnoli and Velicer (1988) recommended that, regardless of sample size, the analysis should retain only those dimensions with four or more loadings above 0.60 in absolute value. Accordingly, given the small sample, the following rules were observed: (1) the minimum number of variables per dimension was four, (2) the minimum absolute magnitude of the loadings for a four-variable dimension was 0.60 , and (3) dimensions loaded with three or fewer variables were not retained. This somewhat strict procedure, however, enhances the reliability and interpretability of the dimension.

\subsection{Instrumentations}

The study used a constructed survey on training programs in learning and teaching by an anonymous higher education leadership program for data collection. It consisted of two main sections. The first section comprised on demographic characteristics and backgrounds of the participants. The second section consisted of 18 items on issues in teaching and learning in participants' classrooms and covers their job as lecturers at their own institutions after attending the various workshops. The assessment is measured on a 5 -point Likert scale, ranging from 1 (Strongly Agree) to 5 (Strongly Disagree).

\subsection{FINDINGS AND RESULTS}

The current data, apparently, displayed no serious departure from normality. In other words, the Skewness and Kurtosis were within the limit of normal distribution (Kline, 2011). In terms of the internal consistency value, the Cronbach's alpha is 0.92 , which indicated the stability of the instrument. Nevertheless, the Corrected Item-Total Correlation gave some signs of poor items (Item 9 and Item 10), which were below 0.3 (Field, 2009). Provided that the Cronbach's Alpha if Item Deleted of Item 9 and Item 10 were exceeding the overall Cronbach's alpha (Table 1). Thus, these two items would be the candidate items for exclusion.

Table 1. Descriptive Statistics and Item Analysis of the Instrument

\begin{tabular}{ccccccc}
\hline Item & Mean & Std. Deviation & Skewness & Kurtosis & $\begin{array}{c}\text { Corrected } \\
\text { Item-Total } \\
\text { Correlation }\end{array}$ & $\begin{array}{c}\text { Cronbach's Alpha if } \\
\text { Item Deleted }\end{array}$ \\
\hline i1 & 2.03 & .784 & 1.567 & 4.270 & .622 & .922 \\
i2 & 2.22 & .784 & 1.074 & 1.769 & .614 & .922 \\
i3 & 2.28 & .849 & .724 & 1.206 & .719 & .920 \\
i4 & 2.15 & .760 & .892 & 1.922 & .770 & .919 \\
i5 & 2.28 & .885 & .659 & .799 & .631 & .922 \\
i6 & 2.04 & .747 & .995 & 2.545 & .714 & .920 \\
i7 & 2.30 & .827 & .786 & 1.446 & .802 & .918
\end{tabular}




\begin{tabular}{lllllll} 
i8 & 2.32 & .714 & .454 & .208 & .774 & .919 \\
i9 & 2.55 & 1.081 & .650 & -.053 & .283 & .933 \\
i10 & 2.92 & 1.089 & -.175 & -.746 & .083 & .938 \\
i11 & 2.47 & .904 & .596 & .262 & .512 & .925 \\
$\mathrm{i} 12$ & 2.29 & .737 & .382 & .089 & .783 & .919 \\
$\mathrm{i} 13$ & 2.31 & .787 & 1.045 & 2.182 & .715 & .920 \\
$\mathrm{i} 14$ & 2.21 & .709 & .287 & .102 & .787 & .919 \\
$\mathrm{i} 15$ & 2.30 & .813 & .330 & .443 & .741 & .920 \\
$\mathrm{i} 16$ & 2.07 & .764 & .368 & -.112 & .687 & .921 \\
$\mathrm{i} 17$ & 2.29 & .737 & .747 & 1.556 & .686 & .921 \\
$\mathrm{i} 18$ & 2.25 & .738 & .114 & -.265 & .667 & .921 \\
\hline
\end{tabular}

\subsection{Exploratory Factor Analysis (EFA)}

To identify the underlying dimensions measured by the variables, an Exploratory Factor Analysis (EFA) which is rather appropriate for the development of a new instrument (Worthinton \& Whittaker, 2006) by employing principal axis factoring (PAF) with Promax normalized rotation (Meyers, Gamst, \& Guarino, 2013; Matsunaga, 2011). Second, the factor loadings were estimated, and to increase the interpretability of the dimension. The approach is consistent with the assumption that the underlying constructs are conceptually related, and with the need to arrive at the simplest factor structure. Third, the Kaiser's criterion for important factors based on the more than 1 Eigenvalue (Kaiser, 1958), Catell's scree test (Catell, 1966), significant factor loadings, and the interpretability of the extracted factors were used to decide the number of dimensions to be retained. Finally, estimating the internal consistency of the retained dimension by observing the Cronbach's alpha index.

The EFA was performed to determine the underlying dimension represented in the 18 items generated to address the issues in teaching and learning after attending various workshops. At this point, all cases of cross-loadings and low-loadings were treated which led to the removal of 6 items from the final output, namely: Item 4 (I can practice/have been practice the classroom skills I learned), Item 5 (I've been using the lessons learnt in my training of others at my institution), Item 8 (I've started using the pertinent skills learnt in my classroom), Item 9 (I think the administrative duties impede my ability to implement what I've learned), Item 11 ( My institution now gives positive support for me to share what I've learned), and Item 18 (My students tend to learn better when I use my new skills). The remaining 12 items produced one factor solution and explained $58.55 \%$ of the total variability (Table 2), which is defensible in a real study (Hair, Black, Babin \& Anderson, 2010; Tabachnick \& Fidell, 2001). Kaiser-Meyer-Olkin Measure of Sampling Adequacy was 0.903, which is respectable, with significant Bartlett's Test of Sphericity $\left(\chi^{2}=741.78, \mathrm{p}=.000\right)$ for the means of factorability.

Table 2. Proportion of Variance Explained

\begin{tabular}{ccccccc}
\hline \multirow{2}{*}{ Component } & \multicolumn{3}{c}{ Initial Eigenvalues } & \multicolumn{2}{c}{ Extraction Sums of Squared Loadings } \\
\cline { 2 - 6 } & Total & \% of Variance & Cumulative \% & Total & \% of Variance & Cumulative \% \\
\hline 1 & 7.43 & 61.89 & 61.89 & 7.026 & 58.55 & 58.55 \\
2 & .98 & 8.15 & 70.04 & & \\
3 & .66 & 5.49 & 75.53 & & \\
\hline
\end{tabular}


Therefore, the result suggested a reasonable one-factor solution with these 12 items. Thereafter, the result showed that the overall Cronbach's alpha coefficient was 0.94 which getting better than the initial item pool. It indicates high internal consistency for the instrument. In light of the factors loadings consideration from Pattern Matrix (Table 3), the result shows that the one-factor solution has significant loadings above the threshold value from 0.66 to 0.83 . The communalities were also above threshold value (above 0.40 ) from 0.43 to 0.70 (Worthinton \& Whittaker, 2006), which implied adequate common variance was explained in this simple structure.

Table 3. The Factor Loadings and Communalities of One-Factor Solution of the Instrument

\begin{tabular}{|c|c|c|}
\hline Items & $\begin{array}{l}\text { Factor } \\
\text { Loading }\end{array}$ & Communality \\
\hline 1. My knowledge in the content area has increased. & .67 & .44 \\
\hline 2. I am equipped with relevant knowledge to my area of specialization. & .66 & .43 \\
\hline 3. My teaching skills are clearly improved. & .78 & .60 \\
\hline 6. I intend to use/apply what I've learned in my classroom. & .75 & .56 \\
\hline $\begin{array}{l}\text { 7. I've begun to make new changes to my teaching \& learning in my } \\
\text { classes. }\end{array}$ & .83 & .70 \\
\hline $\begin{array}{l}\text { 12. I've done things differently in my classroom with the new } \\
\text { knowledge I learnt. }\end{array}$ & .81 & .65 \\
\hline 13. I've gained confidence with the new skill sets I learnt. & .78 & .60 \\
\hline $\begin{array}{l}\text { 14. I realised positive changes happening in my teaching \& learning in } \\
\text { the classroom. }\end{array}$ & .81 & .66 \\
\hline $\begin{array}{l}\text { 15. I have begun making significant contribution to my institution from } \\
\text { the newly acquired knowledge. }\end{array}$ & .78 & .61 \\
\hline 16. I now actively search for new innovative ways to improve my work. & .69 & .47 \\
\hline 17. My teaching has helped my student to improve their soft skills. & .74 & .55 \\
\hline
\end{tabular}

The inspection on the scree plot (Figure 1) also pointed out that the 12-items instrument represents only one factor solution. Thus, the scree test suggested that the instrument is one factor solution. All estimated factor loadings are large enough to be of practical significance. From the second factor on, the line is almost flat, meaning each successive factor is accounting for smaller and smaller amounts of the total variance. In addition, the analysis produced loadings, all of which were in the same positive directions, and solution that was free from variable-specific factor. Thus, the solution, free from factorial complexity and variable-specific factor, extracted positive loadings. These results enhance our confidence that we are dealing with non-chance loadings. 


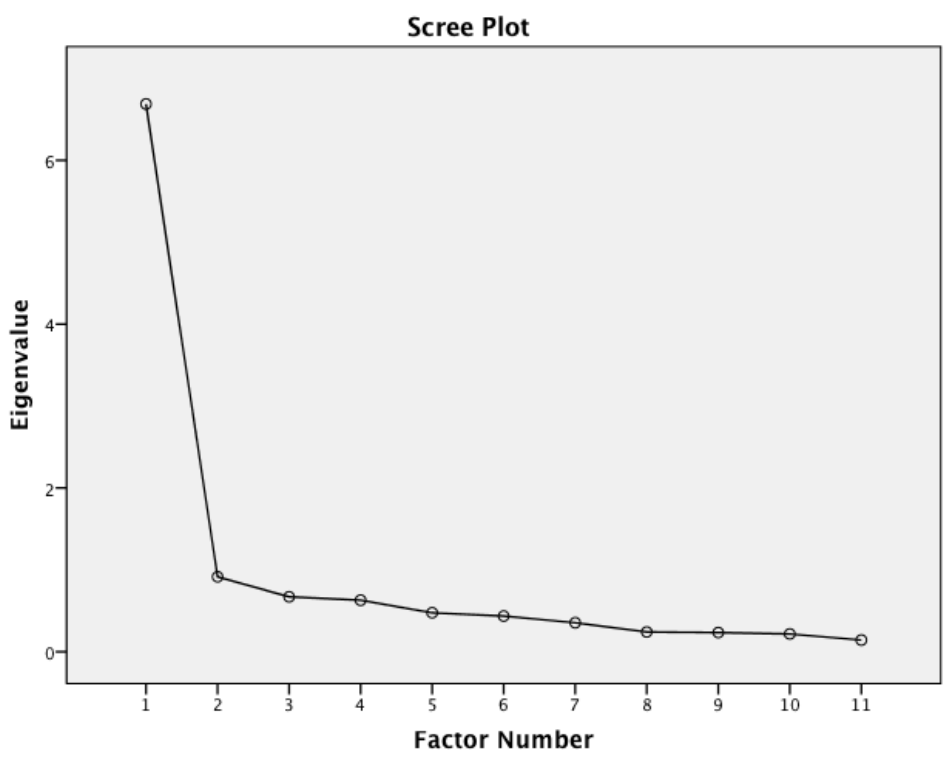

Figure 1. Scree Test

Due to marginal sample size and communalities, the 12 items were subjected to parallel analysis examination (Horn, 1965). It is an extra criterion on how many viable factors should be retained. This procedure is evidence to work fairly well when using EFA (Humphreys \& Montanelli, 1975). The result revealed that the actual eigenvalue (0.978) of the second factor was smaller as compared to the random data eigenvalue (1.4477) from parallel analysis (Table 4). This indicated that only the first actual eigenvalues (7.427) is larger than the random data eigenvalue (1.585). Therefore, we could conveniently suggest that the instrument is one factor solution and unidimensional.

Table 4. Parallel Analysis

\begin{tabular}{cccc}
\hline Factor Number & $\begin{array}{c}\text { Actual Eigenvalue from } \\
\text { EFA }\end{array}$ & Random Eigenvalue & Decision \\
\hline 1 & 7.427 & 1.585 & Accept \\
2 & 0.978 & 1.448 & Reject \\
3 & 0.659 & 1.314 & Reject \\
\hline
\end{tabular}

\subsection{DISCUSSION AND CONCLUSION}

Confined within the limitations of the study, the present results add some new information to the current understanding on lecturers' training, which goes hand in hand with earlier works on this type of training. Clearly, this study suggested that lecturers' professional development instrument is a unidimensional construct. While earlier studies examined the multifaceted dimensions of appropriate content training, relevant professional knowledge, learning attitude, and misaligned practice, the author concern however, was more on how to assess lecturers' orientation towards the improvement of professional development programs as prescribed by Ministry of Higher Education. The researchers postulated that lecturer's professional 
development in teaching and learning is a one-dimension construct, consisting of integrated dimensions of knowledge enhancement, knowledge relevancy, skills improvement, and skills practice.

The results of data analysis are not inconsistent with our own expectations about lecturers' professional development programs. The latent variables jointly explain why a substantial proportion of variances exist in lecturers' responses to the selected items. Knowledge enhancement measures the extent to which a lecturer subscribe to putting skill sets learnt into practice in classroom, intending to use/apply what have had learnt in classroom, beginning to make new changes to teaching and learning in the class, starting using pertinent skills learnt in classroom, having done things differently in classroom with the new knowledge learnt, realizing positive changes happening in teaching and learning in classroom, actively searching for new/innovative ways to improve work, and indicating that students tend to learn better when using new skills in class.

While knowledge relevancy contributes to enhancing knowledge in the content area, equipping with relevant knowledge, improving skills, using lessons learnt in training at relevant institution, and gaining confidence with the new skill sets learnt. Additionally, skills improvement correlates to giving positive support from institution, making significant contribution to institution, and showing improved soft skills via teaching. Additionally, skills practice associates with impeding ability to implement the skills learnt, and administratively preventing from sharing what have been learnt. In summary, the study yielded a finding that lecturers' professional development instrument comprises of four relatively independent scales.

Since the construct is one-dimensional, researcher should not make the mistakes of using composite scores to assign teachers to level of orientation. Rather, the results suggested that researcher use four separate scores - knowledge enhancement, relevant knowledge, skills improvement, and skills practice. A lecturer who scores high on knowledge enhancement may perform poorly on knowledge relevancy, skills improvement, and skills practice. Such a lecturer may strongly value the skills improvement, but he may find it difficult to execute skills practice deemed necessary by the institutions. In this respect, unless we examine each dimension of lecturers' professional development on its own interpretation, we may overlook some important relationships.

The current results have created new paths for research on the lecturers' professional development programs for higher learning institutions in general, and lecturers' improvement in particular. First, there is a need to refine the conception of lecturers' professional development to effectively achieve the goal. Second, further research is necessary to validate and refine the effectiveness of lecturers' professional development programs. Third, it is important to examine factors that influence variability in lecturers' professional development. Finally, research has established evidence to verify the effect of lecturers' professional development to teaching and learning in classroom.

To summarize, the findings from this study must be weighed against the small number of participating lecturers. Thus, future studies should have a larger pool of lecturers. Because this study shows some promises as a means for lecturers to improve their knowledge and capacities, the researchers recommend that future research be directed to the development of an instrument that could provide lecturers with more information on lecturers' training and lecturers' professional development programs.

\section{List of Reference}

Bartlett, J. E., Kortlik, J. W., \& Higgins, C. C. (2001). Organizational Research: Determining Appropriate Sample Size In Survey Research. Information Technology, Learning, and Performance Journal, 19(1), 4350 . 
Bubb, S., \& Earley, P. (2013). The Use of Training Days: Finding Time for Teachers' Professional Development. Educational Research, 55(3), 236-248. DOI: 10.1080/00131881.2013.825161.

Cahill, J., Bowyer, J., Rendell, C., Hammond, A., \& Korek, S. (2015). An Exploration Of How Programme Leaders In Higher Education Can Be Prepared And Supported To Discharge Their Roles And Responsibilities Effectively. Educational Research, 57(3), 272-286.

Cattell, R. B. (1966). The scree test for the number of factors. Multivariate Behavioral Research, 1, 245-276.

Dekker-Groen, A. M., Van Der Schaaf, M. F., \& Stokking, K. M. (2013). A Teacher Competence Development Programme for Supporting Students' Reflection Skills. Teachers and Teaching: Theory and Practice, 19(2), 150-171. DOI: 10.1080/13540602.2013.741837.

Dias, D., \& Sá, M. J. (2014). Transition to Higher Education: The Role of Initiation Practices. Educational Research, 56(1), 1-12.

Field, A. (2009). Discovering statistics using SPSS (3rd ed.). London: Sage Publications.

Gorsuch, R. L. (1983). Factor analysis (2nd ed.). Hillsdale, NJ: Erlbaum.

Guadagnoli, E., \& Velicer, W. (1988). Relation of Sample Size To The Stability Of Component Patterns. Psychological Bulletin, 103, 265-275.

Harland, J., \& Kinder, K. (1997). Teachers' Continuing Professional Development: Framing a Model of Outcomes. Journal of In-Service Education, 23(1), 71-84.

Hair, J. F., Black, W. C., Babin, B. J. \& Anderson, R. E. (2010). Multivariate Data Analysis. New Jersey, NJ: Pearson Education.

Holec, H. (2011). Training Teachers To Cope With The Inherent Variability Of Their Office. Innovation in Language Learning and Teaching, 5(2), 111-118. DOI: 10.1080/17501229.2011.577528.

Horn, J. L. (1965). A Rationale and Test for the Number of Factors in Factor Analysis. Psychometrika, 30, 179-185.

Humphreys, L. G, \& Montanelli, R. G. (1975). An Investigation of the Parallel Analysis Criterion for Determining the Number of Common Factors. Multivariate Behavioral Research, 10, 193-205.

Kaiser, H. F. (1958). The Varimax Criterion for Analytic Rotation in Factor Analysis. Psychometrika, 23, 187-200.

Kirkpatrick, D. L., \& Kirkpatrick, J. D. (2006). Evaluating Training Programs: The Four Levels. San Francisco, CA: Berrett-Koehler Publishers, Inc.

Kirkpatrick, D. L., \& Kirkpatrick, J. D. (2007). Implementing The Four Levels: A Practical Guide For Effective Evaluation Of Training Programs. San Francisco, CA: Berrett-Koehler Publishers, Inc.

LeAD Bulletin (Issue 3, October 2008). AKEPT Quarterly: Higher Education Leadership Academy Bulletin. Putrajaya: Ministry of Higher Education Malaysia.

Matsunaga, M. (2011). How To Factor-Analyze Your Data Right: Do's, Don'ts, and How-To's . International Journal of Psychological Research, 3(1), 97-110.

Meyers, L. S., Gamst, G., \& Guarino, A. J. (2013). Applied Multivariate Research: Design and Interpretation (2nd ed.). London: Sage Publications Ltd.

Pereira, F., Lopes, A., \& Marta, M. (2015). Being a Teacher Educator: Professional Identities And Conceptions Of Professional Education. Educational Research, 57(4), 451-469.

Postholm, M. B. (2012). Teachers' Professional Development: A Theoretical Review. Educational Research, 54(4), 405-429. DOI: 10.1080/00131881.2012.734725.

Page $\mid 90$ 
Schlager, M. S., \& Fusco, J. (2003). Teacher Professional Development, Technology, And Communities Of Practice: Are We Putting The Cart Before The Horse? The Information Society: An International Journal, 19(3), 203-220. DOI: 10.1080/01972240309464.

Subramaniam, K., \& Esprívalo Harrell, P. (2015). An Analysis of Prospective Teachers' Knowledge For Constructing Concept Maps. Educational Research, 57(3), 217-236.

Tabachnick, B., \& Fidell, L. (2001). Using multivariate statistics (4th ed.). Boston: Allyn and Bacon.

Trent, J. (2014). 'I'm Teaching, but I'm Not Really A Teacher'. Teaching Assistants and the Construction of Professional Identities In Hong Kong Schools. Educational Research, 56(1), 28-47.

Worthington, R. L., \& Whittaker, T. A. (2006). Scale Development Research: A Content Analysis and Recommendations for Best Practices. The Counseling Psychologist, 34(6), 806-838. doi:10.1177/0011000006288127. 